\title{
Effect of stress pulse shape on the dynamic fracture of soda-lime glass.
}

\author{
Jaroslav Buchar ${ }^{1 *}$, Jan Trnka ${ }^{1}$ \\ ${ }^{1}$ Institute of Thermomechanics, Czech Academy of Sciences,Prague,Czech Republic
}

\begin{abstract}
The goal of this paper is to evaluate the tensile strength and fracture behavior of the soda lime glass under static and dynamic loading using Brazilian tests. The evaluation of the static tensile strength was performed using the universal testing machine; the fracture behavior under dynamic loading was studied using the Hopkinson Split Pressure Bar (HSPB) Technique. The dynamic loading is realized using the stress pulses of the different shape. In order to obtain the different loading stress pulses impact strikes made from four different materials (Steel, Teflon, Beech, and Polymer) were used. The high-speed camera in both static and dynamic tests was used to obtain some detail view on the failure process of specimens. Experimental results showed that the dynamic tensile strength was at least three times higher than the static one. The initiation of the dynamic fracture occurs when some parameters of the loading stress pulse reaches critical values. These parameters are independent on the stress pulse shape.
\end{abstract}

\section{Introduction}

The knowledge of the fracture properties of glass play significant role in the planning of their use in many practical application when e.g. glass windows are especially vulnerable to shock and impact loading. This kind of loading involves many accidents like terrorist bombing attack, gas explosion, debris impact during windstorm [1] and many others events. This is the reason of the study of the glass and many other brittle materials (concrete, rocks, ceramics) failure behavior under high loading rates corresponding to the problems mentioned above.

The experimental evaluation of the brittle material strength behavior is very complicated due to their brittleness, high hardness, and very small strain to failure. This is the main reason why some alternative experimental methods are used. One of the most popular methods is the Brazilian test which was originally developed for the testing of concrete and rocks [2,3]. This method consists in the loading of a thin circular disk (specimen) by a line compressive line load. This loading generates a tensile stress state inside the specimen. Specimen fails perpendicularly to the diametric loading direction. The evaluation of the stress state in the specimen is very easy during of the static loading under assumption of the pure elastic behavior of the specimen up to the fracture. This method was extended for the dynamic loading using HSPB technique [4]. The evaluation of the results of HSPB method is more complicated than during the static loading. The main problems consist in minimizing the inertial effect, in achievements of dynamic force balance and in deformation specimen at constant loading-rate before failure $[5,6]$. These problems are mostly solved using of the pulse shaper technique. The glass dynamic fracture was studied in papers [7-10], where the main characteristics of this process were obtained.

In the given paper the main attention was focused on the study of the pulse shape effect on the dynamic failure of glass. The shape of the loading (incident) stress pulse was from „half sine“ up to nearly trapezoidal with superimposed oscillations. The detail analysis of the loading stress pulse and response functions parameters was performed. The relation between these parameters and specimen failure behavior was found.

\section{Experimental details}

Soda - lime glass was chosen as testing glass material. Main mechanical properties of this glass are listed in the Table 1.

- Corresponding author: buchar@mendelu.cz 
Table 1. Properties of tested glass.

\begin{tabular}{|c|c|c|c|c|}
\hline $\begin{array}{c}\text { Density } \\
\left(\mathrm{kgm}^{-3}\right)\end{array}$ & $\begin{array}{c}\text { Longitudional wave } \\
\text { velocity } \mathrm{c}_{\mathrm{L}}(\mathrm{m} / \mathrm{s})\end{array}$ & $\begin{array}{c}\text { Shear wave } \\
\text { velocity } \mathrm{c}_{\mathrm{T}}(\mathrm{m} / \mathrm{s})\end{array}$ & $\begin{array}{c}\text { Elastic modulus } \\
\mathrm{E}(\mathrm{GPa})\end{array}$ & Poisson`s ratio $v$ \\
\hline 2490 & 5810 & 3440 & 72.5 & 0.23 \\
\hline
\end{tabular}

The velocities of the longitudinal wave, $\mathrm{c}_{\mathrm{L}}$, and shear wave, $\mathrm{c}_{\mathrm{T}}$, were measured ultrasonically by pulse echo method using Physical Acoustics Corporation $\mu$ DiSP system.

Specimens in form of cylinders, $14 \mathrm{~mm}$ in diameter and $7 \mathrm{~mm}$ in thickness were prepared both for the static and dynamic Brazilian test.

The Brazilian experiments at static loading were performed using universal testing machine (INSTRON 5985).The specimens were compressed at loading-rate of $1 \mathrm{~mm} / \mathrm{min}\left(1.6667 \times 10^{-5} \mathrm{~m} / \mathrm{s}\right)$.

The tensile strength is given by the relation:

$$
\sigma_{t}=\frac{2 P}{\pi D t}
$$

where $\mathrm{P}$ is the maximum loading force at which specimen fails, $\mathrm{D}$ is the specimen diameter and $\mathrm{t}$ is its thickness.

Dynamic Brazilian test was performed using Hopkinson Split Pressure Bar (HSPB) system as schematically shown in the Fig.1.

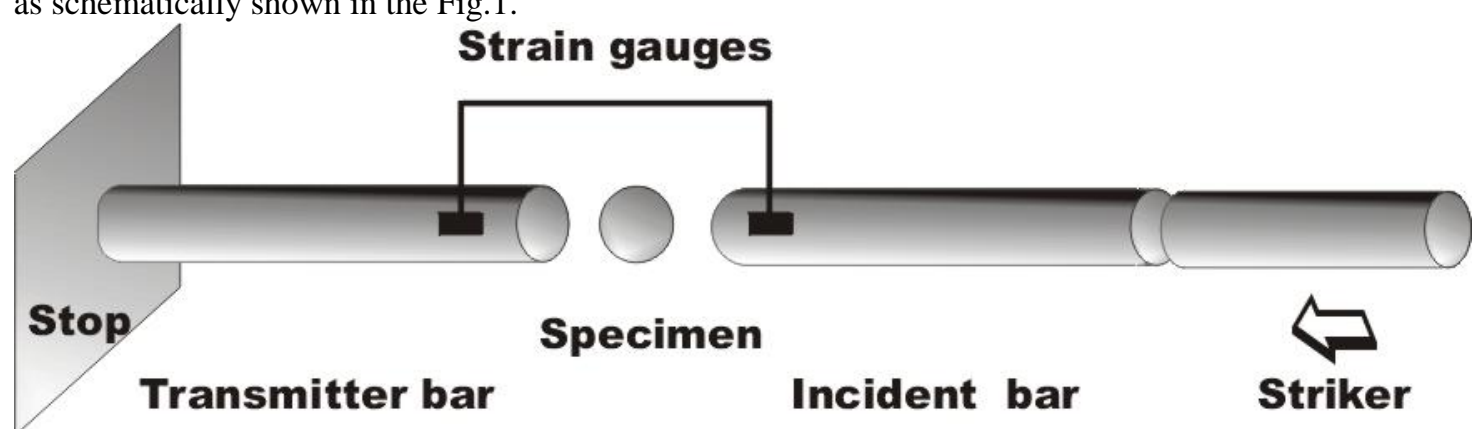

Fig.1. Schematic of the dynamic Brazilian test.

This system consists of three main parts. First of all there is a gas gun enabling to accelerate the projectile (striker) to some velocity. Second part is a system two elastic bars (incident and transmitted) and the third part is the data acquisition system. After impact of the striker on the end of the incident bar the compressive stress pulse (incident stress pulse), $\sigma_{I}(t)$, is developed. After impact of this wave on the interface between the incident bar and specimen some part is reflected back as the reflected stress pulse, $\sigma_{\mathrm{R}}(\mathrm{t})$ and part is transmitted to the second bar as the stress pulse $\sigma_{\mathrm{T}}(\mathrm{t})$.

The maximum value of the incident stress pulse is given by the striking velocity of the striker (projectile). The time duration of the incident stress pulse increases with the striker length. These dependences are different for the different striker materials. In our research the following strikers were used:

- $\quad$ Striker made from the tool steel, $14 \mathrm{~mm}$ in diameter and $32 \mathrm{~mm}$ in length

- Striker made from beech wood, $14 \mathrm{~mm}$ in diameter, $63 \mathrm{~mm}$ in length. The axis of the striker

was oriented in $\mathrm{L}(\equiv 1)$ direction

- $\quad$ Striker made from Teflon, $14 \mathrm{~mm}$ in diameter, 40mm in length

- $\quad$ Striker made from High density polyethylene (HDPE) $15 \mathrm{~mm}$ in diameter, $50 \mathrm{~mm}$ in length.

Steel, Teflon and HDPE were considered as isotropic materials. Beech was considered as the orthotropic material. The bars are made from the tool steel. Diameter of the bars is $15 \mathrm{~mm}$ and their length $1000 \mathrm{~mm}$. Strain gauges were located in the middle of the bars. In the Table 2 the main 
properties of the isotropic materials are given. The material density and wave velocities were determined experimentally. The technique mentioned in the previous section was used.

Table 2. Main properties of the striker's material

\begin{tabular}{llll} 
Properties & STEEL & TEFLON & HDPE \\
\hline Material density $\rho\left(\mathrm{kg} / \mathrm{m}^{3}\right)$ & 7850 & 2150 & 960 \\
\hline $\begin{array}{l}\text { Longitudinal wave velocity, } \\
\mathrm{c}_{\mathrm{L}},(\mathrm{m} / \mathrm{s})\end{array}$ & 6060 & 1230 & 2416 \\
\hline $\begin{array}{l}\text { Shear wave velocity, } \mathrm{c}_{\mathrm{T}}, \\
(\mathrm{m} / \mathrm{s})\end{array}$ & 3150 & 410 & 1010 \\
\hline Elastic modulus, $\mathrm{E},(\mathrm{GPa})$ & 216 & 1.04 & 2.73 \\
\hline Poisson`s ratio, $v$ & 0.31 & 0.437 & 0.39
\end{tabular}

The beech exhibits an orthotropic symmetry. The main acoustic properties of the beech are longitudinal wave velocity in the $\mathrm{L}$ direction $\mathrm{v}_{\mathrm{LL}}=5074 \mathrm{~m} / \mathrm{s}$ and Young`s modulus in $\mathrm{L}$ direction $\mathrm{E}_{\mathrm{LL}}=137 \mathrm{GPa}$. Density of the beech is $674 \mathrm{~kg} / \mathrm{m}^{3}$. Corresponding acoustic impedance is $\mathrm{Z}=3.42 \mathrm{MPas} / \mathrm{m} \quad$ Material density and $c_{\mathrm{L}}$ and $\mathrm{c}_{\mathrm{T}}$ velocities are measured values.

The incident (loading) stress pulse is characterized by the following parameters:

- $\quad$ Maximum of the stress pulse (amplitude) : $\sigma_{\text {Im }}$

- Impulse : $I_{I}=\int \sigma_{I}(t) d t$

- $\quad$ Energy : $w_{I}=\frac{1}{z_{b}} \int \sigma_{I}^{2}(t) d t$

The same parameters were evaluated also for the remaining stress pulses.

The evaluation of the results of the dynamic Brazilian test is based on the assumption of the stress equilibrium before the specimen failure, i.e.. $P_{1}(t)=A_{b}\left[\sigma_{I}(t)+\sigma_{R}(t)\right], P_{2}(t)=A_{b} \sigma_{T}(t)$, where $\mathrm{A}_{\mathrm{b}}$ is the area of the bars. Tensile stress in the center of the glass specimens due to diametric compression is than given by the Eq. (2):

$$
\sigma_{t}=\frac{2 A_{b} \sigma_{T}(t)}{\pi D t}
$$

The specimen loading rate is given as the difference of the velocities of the specimen - bar interfaces, $\mathrm{v}_{1}, \mathrm{v}_{2}[9]$ :

$$
v_{1}=\frac{\sigma_{I}-\sigma_{R}}{z_{b}}, \quad v_{2}=\frac{\sigma_{T}}{z_{b}}, \quad v=v_{1}-v_{2}=\frac{\sigma_{I}-\sigma_{R}-\sigma_{T}}{z_{b}}
$$

The knowledge of the loading rate enables to evaluate the specimens shortening (displacement) according to:

$$
p=\int v d t=\frac{1}{z_{b}} \int\left(\sigma_{I}-\sigma_{R}-\sigma_{T}\right) d t
$$

In order to obtain more information on the specimen behavior impacts themselves were monitored by high speed photography, using PHOTRON FASTCAM SA-Z type 2100K-M, Frame Rate 210000fps, Shutter Speed $1.00 \mu$ s and Resolution 384x160 dpi. All experiments were performed at the room temperature.

\section{Experimental results}

Quasi static loading was performed using the tensile testing machine mentioned in previous chapter. The specimens of glass exhibited brittle behavior. The force F increased with the displacement linearly up to the specimen fracture. The value of the maximum force, $F_{\max }$, is $7132 \pm 768 \mathrm{~N}$, the tensile strength evaluated using Eq. 1 is $46.33 \pm 5.39 \mathrm{MPa}$ and corresponding displacements, $\mathrm{p}_{\mathrm{m}}$, is $0.393 \pm 0.013$ $\mathrm{mm}$. These values represents average from 15 measurements.

The average value of the tensile strength is closed to the value for annealed glass reported in [9].

In the Fig. 2 examples of the loading (input) stress pulses for different strikers and different striking velocities are displayed. It is obvious that the impact of different strikers leads to the development of the stress pulses, $\sigma_{\mathrm{I}}$, of different shapes. The maximum value (amplitude) of the stress pulses, $\sigma_{\text {Imax }}$, increases with the striking velocity, $\mathrm{V}_{0}$. Experimental data can be fitted by the linear function:

$$
\sigma_{\text {Imax }}=a+b V_{0}
$$



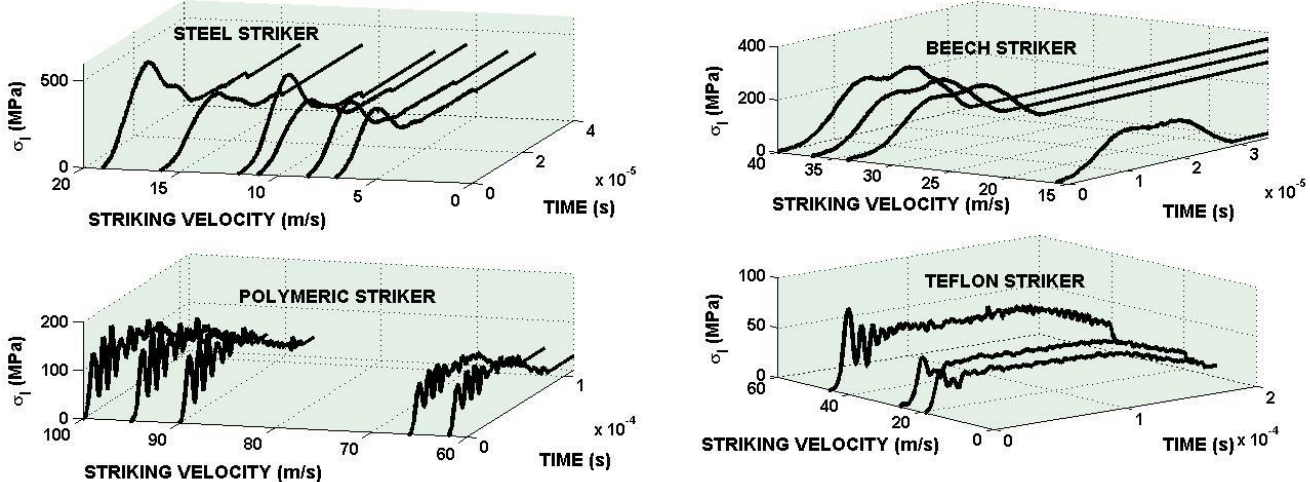

Fig.2. Examples of the input stress pulses, $\sigma_{\text {I }}$ produced by different strikers.

The dependence of impulse, $\mathrm{I}_{\mathrm{I}}$ and energy, $\mathrm{w}_{\mathrm{I}}$, on the striking velocity, $\mathrm{V}_{0}$, can be also fitted by this equation. The parameters of the Eq. 8 are given in the Table 3.

Table 3. Parameters of the Eq.7 ( $\mathrm{R}^{2}$ denotes the coefficient of determination).

\begin{tabular}{llll}
\hline STRIKER & $\mathrm{a}(\mathrm{MPa})$ & $\mathrm{b}(\mathrm{MPas} / \mathrm{m})$ & $\mathrm{R}^{2}$ \\
\hline & AMPLITUDE & & \\
STEEL & 145.8 & 26.28 & 0.9658 \\
BEECH & 99.82 & 2.355 & 0.8959 \\
POLYMER & 7.242 & 1.686 & 0.9979 \\
TEFLON & 10.27 & 1.602 & 0.9782 \\
& IMPULSE & & \\
& $\mathrm{a}(\mathrm{MPas})$ & $\mathrm{b}\left(\mathrm{MPam}^{-1} \mathrm{~s}\right)$ & \\
STEEL & 0.001043 & 0,0006678 & 0.9251 \\
BEECH & 0.001422 & 0,00004858 & 0.9205 \\
POLYMER & 0.001345 & 0.00007728 & 0.9226 \\
TEFLON & -0.03866 & 0,0001832 & 0.9518 \\
& ENERGY & & \\
STEEL & $\mathrm{a}\left(\mathrm{MJm} \mathrm{m}^{-2}\right)$ & $\mathrm{b}\left(\mathrm{MJm}^{-3} \mathrm{~s}\right)$ & \\
BEECH & -0.03866 & 00006678 & 0.9445 \\
POLYMER & 0.000757 & 0.0002567 & 0.9165 \\
TEFLON & -0.004806 & 0.000254 & 0.9109 \\
\hline
\end{tabular}

If we use the steel striker the specimen damage occurs at all striking velocities. The use of the Teflon striker did not lead to the specimen damage. The increase in the striking velocity led to the striker permanent deformation. The maximum of the incident stress was limited. The parameters of the stress pulses $\sigma_{I}$ corresponding to undamaged specimens are reported in the Table 4 .

Table 4. Parameters of the stress pulses recorded for undamaged specimens.

\begin{tabular}{lllll}
\hline STRIKER & $\mathrm{V}(\mathrm{m} / \mathrm{s})$ & $\sigma_{\operatorname{Imax}}(\mathrm{MPa})$ & $\mathrm{I}_{\mathrm{I}}(\mathrm{MPas})$ & $\mathrm{W}_{\mathrm{I}}\left(\mathrm{MJm}^{-2}\right)$ \\
\hline BEECH & 16 & 141.7 & 0.002564 & 0.0070431 \\
& 34 & 166.7 & 0.003158 & 0.0104853 \\
\hline \multirow{3}{*}{ POLYMER } & 62 & 113.3 & 0.00606 & 0.010889 \\
\hline \multirow{2}{*}{ TEFLON } & 66 & 116.7 & 0.006395 & 0.011163 \\
& 19 & 43.3 & 0.005343 & 0.003725 \\
& 26 & 48.3 & 0.006247 & 0.004929 \\
\hline MAXIMUM & 45.5 & 83.3 & 0.009151 & 0.01048 \\
\hline
\end{tabular}


Fig.3 shows example of high speed images of the specimen fracture. The time positions of single images are shown in the Fig.3b where the stress - time history is displayed. Striker velocity was 19 $\mathrm{m} / \mathrm{s}$. The images left side represents to the incident bar -specimen interface and the right part to transmitted bar- specimen interface.
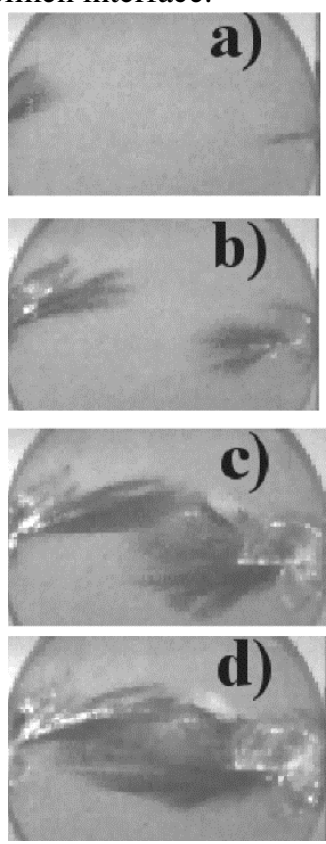
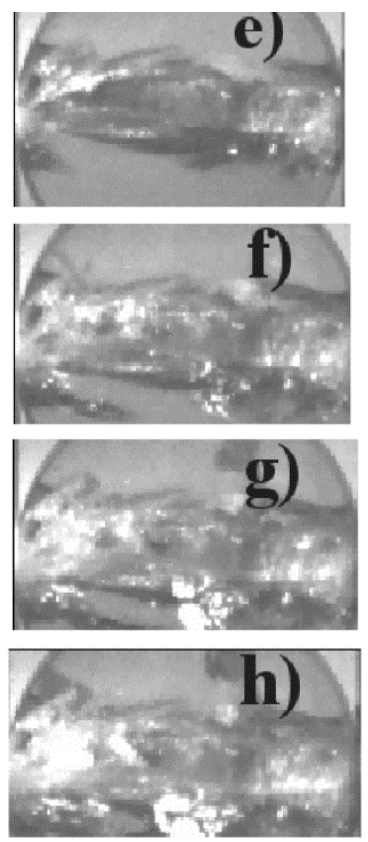

$3 \mathrm{a}$

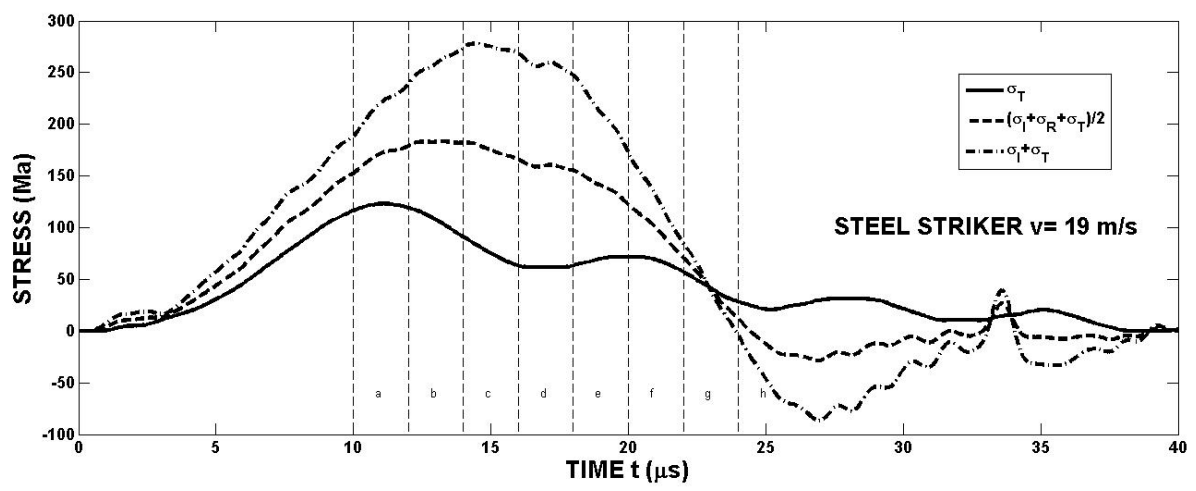

$3 b$

Fig.3 .a- High speed images of failure process in specimen at different times. Steel striker. Striker velocity 19 $\mathrm{m} / \mathrm{s}$. b - Stress - time history. Position of single frames.

First a crack initiated at the contact interface (a). From this crack, two wing-like cracks propagated from the surface of the specimen to the centre, running parallel to the faces of the cylindrical sample (b). Once these cracks reached the midpoint of the specimen, the two wing-like cracks merged and continued to propagate as a single crack, reaching the far end of the specimen (d,e). The inrease of the loading leads to the growth of the specimen damage up to its splitting. It is evident that there is no force equilibrium. The stress in the specimen exhibits significant gradient.

Results show that the main two assumptions used in the dynamic tensile strength evaluation were not satisfied. One reason of this phenomenon may be a consequence of the short pulse duration. The Brazilian tests are performed using stress pulses of more than $100 \mu$ s time duration $[18,19]$. The time duration of stress pulses higher than $100 \mu$ s can be expected if we use other strikers - see Fig. 2 . 
This time duration is achieved for the polymer striker. Fracture of the specimen was observed at the polymer striker impact velocity $90 \mathrm{~m} / \mathrm{s}$. Even if the input stress pulse duration is about $120 \mu \mathrm{s} \mathrm{like} \mathrm{e.g.}$ in many works - see e.g. $[9,10]$ no equilibrium in the specimen was achieved. The obtained results show that the use of the Eq. (2) is very problematic at least. We have three values of the stress maximum: transmitted stress, $\sigma_{\mathrm{T}}$, average stress $\left(\sigma_{\mathrm{I}}+\sigma_{\mathrm{R}}+\sigma_{\mathrm{T}}\right) / 2$ and input stress $\sigma_{\mathrm{I}}+\sigma_{\mathrm{R}}$.

If we use these three values of the stress for the specimens where fracture occurred we obtain values of tensile strength at least three times higher than than values achieved at the quasi static loading. This increase seems to be non realistic.In [9] where the use of Eq. (2) was fully satisfied were found that the dynamic tensile strength is higher than the static one by factor 1.18 . The loading rate was in interval 1 $-4 \mathrm{~m} / \mathrm{s}$. Because the evaluation of the tensile strength using a classical approach - Eq. (4) - is questionable we try to find another quantity describing the fracture behavior. Analysis of the experimental data led to the conclusion that there are some parameters of the stress pulses which are independent on the stress pulse shape. The analysis of the experimental data show that main parameters of the pulses depends on the stresss pulse maximum $\sigma_{\text {Imax }}$ independently on the striker material as :

$w_{I}=4.121 .10^{-7} \sigma_{I \max }^{2}-6.77 .10^{-5} \sigma_{\text {Imax }} 10.01204 \quad R^{2}=0.9815$

Amplitude of the transmitted pulse $: \sigma_{\text {Tmax }}=0.1943 \sigma_{\operatorname{Imax}}+36.65 \quad R^{2}=0.9304$

Amplitude of the reflected stress pulse: $\sigma_{R \min }=-38.86-0.5492 \sigma_{\text {Imax }} \quad R^{2}=0.9635$

Energy of the reflected stress pulse: $w_{R}=-0.004619+6.968 .10^{\{-5\} \sigma_{\text {Imax }}} R^{2}=0.9429$

Experimental data presented in the Table 4 represent critical values for the fracture of the specimens. For example the critical value of the stress pulse energy is $0.011163 \mathrm{MJm}^{-2}$. The damage starts for the incident stress pulse with this energy.

\section{Conclusions}

The experimental research on the dynamic fracture of glass using indirect tensile (Brazilian) test was performed. The dynamic fracture was studied using classical Hopkinson split pressure bar. Four different strikers were used. The loading stress pulses exhibit different stress - time histories starting from "half - sine" up to trapezoidal with superimposed oscillations. The duration of these pulses changes from about $30 \mu$ s up to about $120 \mu$ s.

During the all tests no force equilibrium in the specimen was achieved. This fact was also documented by observation of the fracture behavior using high speed camera. There were no differences in the qualitative features of the damage growth in the specimen loaded by the stress pulses of different shape. The use of classical equation - see Eq. (2) - led to some unrealistic increase in the tensile strength in comparison with the static one.

Analysis of the results showed that the fracture starts if the parameters of the input stress pulse achieve some critical values. These values are independent on the striker material properties.

Acknowledgements: This research was supported by the European Regional Development Fund under Grant No. CZ.02.1.01/0.0/0.0/15_003/0000493 (Centre of Excellence for Nonlinear Dynamic Behavior of Advanced Materials in Engineering).

\section{References.}

1. H.S. Norville,N. Harvill, E.J. Conrath, S.Shariat, J. Perform. Constr. Facil.13,50 (2012)

2. S. Carmona, A.Aguado, Mater. Struct. 45,1473(2012)

3. D.Li ,L.N.Y. Wong, Rock Mech. Rock Eng. 46,269(2013)

4. T.Saksala ,M. Hokka ,V.T. Kuokkala, et al., Int J Rock Mech Mining Sci 59,128 (2013)

5. J.J.Chen ,B.Q. Guo,H.B. Liu, et al. , Strain 50,563 (2014)

6. D.J. Frew,M.J. Forrestal ,W. Chen, Exp. Mech. 42,93 (2002)

7. X. Nie,W. Chen, Ceramic and Engineering Science Proceedings, 28,103(2007)

8. M. Peroni , G. Solomos ,V. Pizzinato ,M. Larcher, App)l. Mech. Mater. 82,63(2011).

9. M.Z. Sheikh et al., J. Non-Cryst. Solids 499,189 (2018).

10. M. Z. Sheikh, Zhen Wanga, Bing Dua, Tao Suoa et al., Ceramics International 45,7931 (2019). 